\title{
Perceived competence in adolescent medicine practice and paediatrics sub- specialty preferences of Nigerian medical practitioners
}

\author{
Moses Temidayo Abiodun ${ }^{1}$, Austin Omoigberale ${ }^{2}$, Micheal Ibadin ${ }^{3}$
}

Sri Lanka Journal of Child Health, 2014; 43(3): 163-167

\begin{abstract}
Background: Adolescent medicine (AM) is a field in paediatrics that provides comprehensive healthcare to adolescents, considering their transitional stage in development.
\end{abstract}

Objectives: We examined perception of AM among medical officers and house officers in paediatrics, their perceived competence in AM practice, and their paediatrics subspecialty preferences.

Method: It is a descriptive cross-sectional study. Participants' views, perceived competence in AM and subspecialty preferences were determined using a five-item Likert scale on a self-administered questionnaire. Pearson's Chi-square was used to assess any association between perceived competence and gender/ duration of clinical practice.

Results: Of the 42 clinicians enrolled, $57 \%$ were males, $46 \%$ were practising in Teaching Hospitals, and nearly $67 \%$ were from South-South geopolitical zones. About $60 \%$ participants reported that they were 'more competent' in managing adolescents while $19 \%$ perceived they were 'less competent' with this age group. However, 8 out of every 10 study participants expressed need for further training in AM. Clinicians' gender, duration of clinical practice and practice setting did not influence their perceived competence in AM ( $p>0.05)$. Emergency paediatrics $(68 \%)$, respiratory unit $(63 \%)$ and AM $(49 \%)$ were the 'more preferred' subspecialties.

Conclusion: There is an apparently high level of AM competence and preference among the clinicians.

(Key words: Adolescent medicine; perceived competence; medical practitioners)

${ }^{1}$ Consultant Paediatrician, ${ }^{2}$ Professor of
Neonatology, ${ }^{3}$ Chief Medical Director, Department
of Child Health, University of Benin Teaching
Hospital, Benin City, Nigeria

(Received on December 2013: Accepted after revision on 21 February 2014)

\section{Introduction}

Adolescent medicine (AM) is a field in paediatrics providing comprehensive healthcare to adolescents, considering their transitional stage in development ${ }^{1}$. Physical and sexual maturity often exceeds psychosocial development of adolescents, predisposing them to psychosocial disequilibrium and youth risk behaviour ${ }^{2}$. This is one of the main factors underlying the high level of teenage morbidities and deaths around the world. Hence, adolescent physicians, as well as youth-friendly services and facilities, are necessary in our societies. There are about 30 million adolescents in Nigeria at risk of various behavioural, reproductive and general health issues $^{3}$. They resent being treated as young children and seldom seek help willingly from adult physicians. Hence, paediatricians with interest in AM and every healthcare provider should possess skills pertinent to provision of AM services at every facility especially in our setting ${ }^{1}$.

However, current undergraduate medical education in Nigeria under-emphasizes AM. Limited specific training is provided on the wide spectrum of health problems of adolescents. Also, until recently, AM was not prominent in paediatrics residency training in Nigeria $^{4,5}$. Moreover, coverage of curriculum content related to AM, physical infrastructures, and numbers of faculty available for AM training are rated as suboptimal in Nigerian post-graduate medical education'. Hence, the open questions are: 'What is the current level of competence of Nigerian medical practitioners in AM?' 'How many young clinicians are willing to pursue a career in AM?' There are no research works answering the above questions in Nigeria at present.

\section{Objectives}

To determine the perceived competence in AM practice among medical officers (MOs) with interest in paediatrics, and house officers (HOs) in paediatrics posting at the University of Benin Teaching Hospital (UBTH), Nigeria, the factors influencing it and their preferred areas of sub-specialization in paediatrics. 


\section{Method}

Design: This is a cross-sectional descriptive survey.

Setting and participants: Study was carried out from $19^{\text {th }}$ February to $4^{\text {th }}$ March 2013 at the Multipurpose Hall of Oba Akenzua Complex at the UBTH, Benin City, Nigeria. Participants were MOs preparing for the Primary Examination of the National Postgraduate Medical College of Nigeria, attending the Intensive Course in Paediatrics of the College. Also HOs in paediatrics posting in the hospital at this time were recruited. Permission was sought from the Local Organizing Committee of the revision course and the Head of Department of Child Health, UBTH. Informed consent was obtained from every study participant. In all, $42 \mathrm{HOs}$ and MOs were selected by simple random sampling.

Data collection: The main instrument designed for the study was a self-administered questionnaire on clinicians' perception of AM and subspecialty preference. Questionnaire contained 4 sections: (a) clinicians' socio-demographic and practice characteristics (b) perception of AM and AM training in undergraduate medical education (c) perceived competence in AM and (d) clinicians' subspecialty preference. Using a five-item Likert scale, options ranged from most competent/preferred to least competent/preferred. Similarly, clinicians' views ranged from strongly agree to strongly disagree.

Statistical analysis: Data was analysed using the software package for social science (SPSS) version 20.0 (Windows Inc; Chicago, IL, USA). Categorized data was presented as proportions. Clinicians' perceived competence, preference and views were reclassified on a three-item scale. Fisher's exact test or Pearson's Chi-square was used to assess for any significant association between perceived competence and gender/ duration of clinical practice. A 2 -sided $\mathrm{p}$-value $<0.05$ was considered significant.

\section{Results}

General participants' characteristics are outlined on Table 1.

Table 1: Socio-demographic and practice characteristics of the respondents $(n=42)$

\begin{tabular}{|l|c|}
\hline \multicolumn{1}{|c|}{ Characteristics } & Frequency (\%) \\
\hline Sex & $24(57)$ \\
Male & $18(43)$ \\
Female & $06(14)$ \\
\hline Duration of clinical practice & $36(86)$ \\
12 months or $>$ & \\
$<12$ months & $06(14)$ \\
\hline Current status & $36(86)$ \\
Medical officers & \\
House officers & $20(47.6)$ \\
\hline Current institution of practice & $17(40.5)$ \\
Federal teaching hospital & $05(11.9)$ \\
State teaching hospital & \\
Others & $05(11.9)$ \\
\hline Geopolitical zone & $02(04.8)$ \\
North East & $02(04.8)$ \\
North West & $04(09.5)$ \\
North Central & $03(07.1)$ \\
South East & $26(61.9)$ \\
South West & \\
South-South &
\end{tabular}

Forty two clinicians were enrolled of whom 57\% were males, $45.7 \%$ were practising in Teaching Hospitals, and nearly two-thirds were from the South-South geopolitical zones.

\section{Adequacy of undergraduate medical education}

Clinician's views of the adequacy of undergraduate medical education (UME) relevant to AM practice are shown in Table 2.

Table 2: Clinicians' view of statements on adequacy of UME relevant to AM practice $(n=42)$

\begin{tabular}{|l|c|c|c|c|c|c|}
\hline \multirow{2}{*}{ Statements } & \multicolumn{5}{c|}{ Clinicians' view } \\
\cline { 2 - 7 } & \multicolumn{2}{|c|}{ Agree } & \multicolumn{2}{c|}{ Indifferent } & \multicolumn{2}{c|}{ Disagree } \\
\cline { 2 - 7 } & $\mathbf{n}$ & $\mathbf{\%}$ & $\mathbf{n}$ & $\mathbf{\%}$ & $\mathbf{n}$ & $\mathbf{\%}$ \\
\hline UME adequately prepare doctors to manage adolescents n=39 & 14 & 35.9 & 8 & 20.5 & 17 & 43.6 \\
\hline $\begin{array}{l}\text { There is no specific teaching on the management of } \\
\text { adolescents in UME n=36 }\end{array}$ & 21 & 58.3 & 4 & 11.1 & 11 & 30.6 \\
\hline $\begin{array}{l}\text { The medical graduate is not prepared to manage health risk } \\
\text { behaviour in adolescents n = 42 }\end{array}$ & 17 & 40.5 & 13 & 31.0 & 12 & 28.6 \\
\hline $\begin{array}{l}\text { All GP's need further training in order to competently manage } \\
\text { adolescents n = 42 }\end{array}$ & 34 & 81.0 & 8 & 19.0 & 0 & 0.0 \\
\hline
\end{tabular}

$U M E=$ Undergraduate medical education; $G P=$ general practitioners 
Only $36 \%$ of the participants agreed that UME adequately prepare medical practitioners to manage adolescents. However, $40.5 \%$ expressed this same view on the management of health risk behaviour in adolescents. Eight out of every 10 study participants expressed the need for further training in order to competently manage adolescents.

\section{Clinicians' perceived competence}

Nearly $60 \%$ of the participants reported that they were 'more competent' in managing adolescents while $19 \%$ perceived they were 'less competent' with this age group. The highest perception of low competence $(33.3 \%)$ was in newborn care (Table 3 ).

Table 3: Clinicians' perceived competence in health care delivery in different patients' age groups $(n=42)$

\begin{tabular}{|c|c|c|c|c|c|c|}
\hline \multirow{3}{*}{ Patients' age group } & \multicolumn{6}{|c|}{ Perceived competence } \\
\hline & \multicolumn{2}{|c|}{ More competent } & \multicolumn{2}{|c|}{ Competent } & \multicolumn{2}{|c|}{ Less competent } \\
\hline & $\mathbf{n}$ & $\%$ & $\mathbf{n}$ & $\%$ & $\mathbf{n}$ & $\%$ \\
\hline Neonates & 15 & 35.7 & 13 & 31.0 & 14 & 33.3 \\
\hline Infants & 19 & 45.2 & 14 & 33.3 & 9 & 21.4 \\
\hline Pre-school & 23 & 54.8 & 17 & 40.5 & 2 & 4.8 \\
\hline School age & 25 & 59.5 & 12 & 28.6 & 5 & 11.9 \\
\hline Adolescents & 25 & 59.5 & 9 & 21.4 & 8 & 19.0 \\
\hline
\end{tabular}

Excluding infants and neonates, clinicians were more likely to describe themselves as more competent in 'pre-adolescent care' than in 'adolescent healthcare' $(69.4 \%$ vs $30.6 \%)$, but this did not attain statistical significance $(\mathrm{p}=0.08, \mathrm{OR}=2.588,95 \% \mathrm{CI}=0.9$ 7.7). There was no significant difference in perceived competence in AM between southern and northern as well as federal and state clinicians $(\mathrm{p}>0.05)$.

Moreover, study participants' views on the adequacy of undergraduate training related to AM did not influence their perceived competence in adolescent health care delivery $(p>0.05)$. Similarly, clinicians' gender and duration of clinical practice did not influence perceived competence in AM in this survey $(\mathrm{p}>0.05)$

\section{Clinicians' view of Adolescent Medicine practice}

Approximately three-quarters of the study participants agreed that adolescents should be managed by paediatricians $(76.2 \%)$ and that screening adolescents for health risk behaviour can be incorporated into routine medical practice $(75.6 \%)$. At least seven out of every ten clinicians in this survey identified the scope of AM to include management of behavioural disorders, reproductive health issues and counselling of parents/guardians. Further details of the participants' view are shown in Table 4.

Table 4: Clinicians' views of statements on adolescent medicine practice $(n=42)$

\begin{tabular}{|l|l|l|l|l|l|l|l|}
\hline \multirow{2}{*}{ Statements } & \multicolumn{6}{c|}{ Clinicians' views } \\
\cline { 2 - 7 } & \multicolumn{2}{|c|}{ Agree } & \multicolumn{2}{c|}{ Indifferent } & \multicolumn{3}{c|}{ Disagree } \\
\cline { 2 - 7 } & $\mathbf{n}$ & $\mathbf{\%}$ & $\mathbf{n}$ & $\mathbf{\%}$ & $\mathbf{n}$ & $\mathbf{\%}$ \\
\hline Adolescents should be managed by adult physicians & 19 & 45.2 & 8 & 19.0 & 15 & 35.7 \\
\hline Adolescents should be managed by paediatricians & 32 & 76.2 & 3 & 7.1 & 7 & 16.7 \\
\hline Adolescents require special attention & 39 & 92.9 & 3 & 7.1 & 0 & 0.0 \\
\hline Adolescent health problems are often preventable & 34 & 81.0 & 8 & 19.0 & 0 & 0.0 \\
\hline $\begin{array}{l}\text { Screening of adolescents for health risk behavior can be done } \\
\text { in routine medical practice }\end{array}$ & 31 & 75.6 & 6 & 14.6 & 4 & 9.8 \\
\hline AM can manage behavioural disorders & & & & & & \\
\hline AM can manage reproductive health issues & 34 & 81.0 & 5 & 11.9 & 3 & 7.1 \\
\hline $\begin{array}{l}\text { Counseling of parents/guardians is major aspect of adolescent } \\
\text { health care delivery }\end{array}$ & 29 & 69.0 & 7 & 16.7 & 6 & 14.3 \\
\hline
\end{tabular}

\section{Paediatrics sub-specialty preferences}

The 'more preferred' subspecialties were Emergency Paediatrics (68.3\%) and Respiratory Unit (63.4\%). Also, almost half of the respondents $(48.8 \%)$ rated
AM as more preferred. Less preferred subspecialties were Haemato-oncology (41.5\%) and Neurology (38.5\%). Less than $10 \%$ of the participants expressed their perception of neonatology. Details of the clinicians' preferences are shown in Table 5. 
Table 5: Paediatrics sub-specialty preferences of the study participants

\begin{tabular}{|l|c|c|c|c|c|c|}
\hline \multirow{2}{*}{ Paediatrics subspecialty } & \multicolumn{7}{|c|}{ Clinicians' preference } \\
\cline { 2 - 7 } & \multicolumn{2}{|c|}{ More preferred } & \multicolumn{2}{c|}{ Preferred } & \multicolumn{2}{c|}{ Less preferred } \\
\cline { 2 - 8 } & $\mathbf{n}$ & $\mathbf{\%}$ & $\mathbf{n}$ & $\mathbf{\%}$ & $\mathbf{n}$ & $\mathbf{\%}$ \\
\hline Adolescent Medicine $\mathrm{n}=41$ & 20 & 48.8 & 10 & 24.4 & 11 & 26.8 \\
\hline Emergency Paediatrics $\mathrm{n}=41$ & 28 & 68.3 & 5 & 12.2 & 8 & 19.5 \\
\hline Gastroenterology $\mathrm{n}=40$ & 18 & 45.0 & 13 & 32.5 & 9 & 22.5 \\
\hline Nephrology $\mathrm{n}=40$ & 12 & 30.0 & 17 & 42.5 & 11 & 27.5 \\
\hline Neurology $\mathrm{n}=39$ & 10 & 25.6 & 14 & 35.9 & 15 & 38.5 \\
\hline Haemato-oncology $\mathrm{n}=41$ & 12 & 29.3 & 12 & 29.3 & 17 & 41.5 \\
\hline Respiratology $\mathrm{n}=41$ & 26 & 63.4 & 9 & 22.0 & 6 & 14.6 \\
\hline Neonatology $\mathrm{n}=3$ & 3 & 100.0 & - & - & - & - \\
\hline
\end{tabular}

\section{Discussion}

Clinical competence is pertinent to optimal health care delivery in all age groups, especially among adolescents who are at a sensitive stage of development and often report important unmet health care needs as well as unwillingness to seek perceived needed care from their physicians ${ }^{6-8}$. A majority of our respondents perceived themselves as competent in the management of adolescents irrespective of their practice setting. This could be a reflection of the aspects of adolescent healthcare being provided by these clinicians. A larger proportion $(85.7 \%)$ of our participants are house officers whose job descriptions often include basic clinical evaluation and minor invasive procedures, like venepuncture. The foregoing is relatively simpler among adolescents than in the younger age group, after adequate counseling. The fact that newborn care was their main area of low competence supports the above view. Also, this survey did not elicit specific AM services being provided by the respondents.

Nonetheless, the relatively high competence in adolescent healthcare expressed by these medical practitioners did not correlate with their prior exposure to some aspects of AM during undergraduate training. Doctors who received 'specific teaching in AM' and are 'well prepared to manage health risk behaviour' did not rate themselves as 'more competent' than others in adolescent care. In contrast, Mark et $\mathrm{al}^{6}$ found that having at least some training in AM correlates positively with the provision of anticipatory guidance and perceived competence in managing problems related to sexuality and sexual abuse. Sociodemographic and practice characteristics did not consistently influence perceived AM competence in this survey, comparable to the findings among Nigerian paediatric residents 9 .
Almost all of our respondents ( $81 \%$ ) confirmed that there is a need for further training of all general medical practitioners in order to competently manage adolescents. This highlights the increasing need for AM experts in the country. Considering the high adolescent population and prevalent morbidities in our sub-region, availability of sub-specialists in adolescent health care is a necessity rather than luxury ${ }^{2,10}$. Hence, there is a dire need in various training institutions to strengthen their AM clinical rotations at both undergraduate and post-graduate levels so that all clinicians can be proficient in adolescent health care delivery ${ }^{5}$.

Interestingly, nearly half of our respondents agreed that adolescents should likewise be managed by adult physicians. This is similar to the initial reactions among clinicians when American Academy of Paediatrics redefined the scope of paediatricians to extend to the $21^{\text {st }}$ birthday ${ }^{6-11}$. Unhealthy self-image and lack of knowledge are potential obstacles to healthcare delivery to adolescents. In a USA survey among paediatricians, being perceived as 'baby doctor' was cited by $62 \%$ of the respondents as obstacles to optimal adolescent care ${ }^{6}$. However, paediatrician's developmental perspective appears to be uniquely suited to the task of providing care to adolescents ${ }^{6}$. Individual paediatricians must develop mechanisms to boost AM services delivery. This would include: provision of adolescent-friendly services, enhanced proficiency and expanding one's referral network to accommodate the complex needs of adolescents ${ }^{12}$. In this study, at least seven out of ten participants correctly identified the scope of AM services, similar to the findings in another Nigerian physician survey ${ }^{9}$.

Modest interest was shown in AM as the subspecialty of choice in this survey. More preferred subspecialties include emergency paediatrics and respiratory unit. This could be partly due to the awfully low level of professionals and facilities 
devoted to AM in Nigeria at present ${ }^{5}$. Hence, medical graduates are relatively ignorant of the prospects in this novel field of paediatrics. There is need to extend the on-going activation of AM training (especially adolescent preventive service) to undergraduate level, considering that curative care alone cannot improve our health indices ${ }^{13,14}$.

\section{Conclusions and recommendations}

This survey found an apparently high level of AM competence among the clinicians, independent of their personal and practice characteristics, as well as undergraduate AM experience. It is also one of their preferred subspecialties. There is a need to describe the current practice of specific AM components among Nigerian non-expert medical professionals.

\section{Acknowledgements}

The authors thank Drs. Paul Ikhuirona, Torty, EkiUdoko and Oduebor who participated in data collection.

\section{References}

1. Jenkins RR. Delivery of healthcare to adolescents. In: Kliegman RM, Behrman RE, Jenson HB, editors. Nelson Textbook of Pediatrics $18^{\text {th }}$ ed. Philadelphia: Saunders Elsevier; 2007. p. 111.

2. Nwokocha ARC. Adolescence and associated problems In Azubike JC, Nkanginieme KEO, editors Paediatrics and Child Health in a Tropical Region $2^{\text {nd }}$ ed. African Educational Services, Owerri: 2007: p 91-100.

3. UNICEF Fact Sheet 2010: Young People's Health and Development in Nigeria; accessed $22^{\text {nd }}$ June 2013.

4. West African College Of Physicians (WACP) Faculty of Paediatrics Training Curriculum; pp $1-28$.

5. Abiodun MT, Omoigberale AI, Ibadin MO. Evaluation of Adolescent Medicine Subspecialty Training in Nigeria: Trainees' Perspectives. EAMJ (in review)
6. Marks A, Fisher M, Lasker S. Adolescent medicine in paediatric practice. Journal of Adolescent Health Care 1990; 11: 149-53. http://dx.doi.org/10.1016/0197-0070(90)90026$\underline{X}$

7. Marks A, Malizio J, Hoch J, Brody R, Fisher M. Assessment of health needs and willingness to utilize health care resources of adolescents in a suburban population. Journal of Pediatrics 1983; 102: 456-60. http://dx.doi.org/10.1016/S0022-3476(83)80677$\underline{5}$

8. Hassan A, Blood EA, Pikcilingis A, Krull EG, McNickles L, et al. Youths' health-related social problems: concerns often overlooked during the medical visit. Journal of Adolescent Health 2013. pii: S1054-139X(13)00148-1.

9. Abiodun MT, Omoigberale AI, Ibadin MO. Current practice of Adolelescent Preventive Services among paediatrics residents in Nigeria. SAJCH (in review).

10. Robertson B, Omigbodun O, Gaddour N. Child and adolescent psychiatry in Africa: luxury or necessity? African Journal of Psychiatry 2010; 13: 329-31.

11. Council on Child Health. Age limits of pediatrics. Pediatrics 1972; 49: 463.

12. Committee on Practice and Ambulatory Medicine, American Academy of Pediatrics: Management of Pediatrics Practice. Elk Grove Village, IL, 1986.

13. Nkanginieme KEO, Nte AR. Preventive Paediatrics. In Azubike JC, Nkanginieme KEO, editors Paediatrics and Child Health in a Tropical Region $2^{\text {nd }}$ ed. African Educational Services, Owerri: 2007: 21-27.

14. National Strategic Framework on the Health \& Development of Adolescents \& Young People in Nigeria (2007-2011) Federal Ministry of Health, Abuja, Nigeria; pp 1-128. 